\title{
Research on the Grain Boundary Liquation Mechanism in Heat Affected Zones of Laser Forming Repaired K465 Nickel-Based Superalloy
}

\author{
Qiuge $\mathrm{Li}^{1}$, Xin Lin ${ }^{1, *}$, Xinghua Wang ${ }^{2}$, Haiou Yang ${ }^{1}$, Menghua Song ${ }^{1}$ and Weidong Huang ${ }^{1}$ \\ 1 State Key Laboratory of Solidification Processing, Northwestern Polytechnical University, Xi'an 710072, \\ China; qiuge321626@163.com (Q.L.); yanghaiou@nwpu.edu.cn (H.Y.); songmenghua@163.com (M.S.); \\ huang@nwpu.edu.cn (W.H.) \\ 2 Luoyang Ship Material Research Institute, Luoyang 471023, China; wangxh1717@126.com \\ * Correspondence: xlin@nwpu.edu.cn; Tel.: +86-29-88460510; Fax: +86-29-88495106
}

Academic Editor: Johan Moverare

Received: 27 January 2016; Accepted: 29 February 2016; Published: 15 March 2016

\begin{abstract}
The damaged K465 nickel-based superalloy parts were repaired by laser forming repair technology. The cracking characteristics and grain boundary liquation in heat affected zones were investigated by optical microscopy (OM), scanning electron microscopy (SEM), and transmission electron microscopy (TEM). It was found that the cracks originated from the heat-affected zone and extended to the repaired zone. The calculation by Thermol-Cale software showed that the larger $\gamma^{\prime}$ particles at grain boundaries partly dissolved in the $\gamma$ phase, which made the solutes' concentration at the $\gamma^{\prime} / \gamma$ interface meet the eutectic-type liquation reaction condition of $\gamma+\gamma^{\prime} \rightarrow$ L. Then, grain boundaries liquation occurred and liquid films appeared with the temperature increasing in a rapid heating process. However, the intragranular $\gamma^{\prime}$ phase completely dissolved into the $\gamma$ phase with no devotion to the liquid film. The dissolution of $\mathrm{M}_{5} \mathrm{~B}_{3}$ borides at grain boundaries could promote grain boundary liquation.
\end{abstract}

Keywords: laser forming repairing; K465 nickel-based superalloy; cracking; grain boundary liquation; $\gamma^{\prime}$ phase

\section{Introduction}

K465 superalloy is a kind of cast nickel-based superalloy strengthened primarily by precipitation of ordered $\mathrm{L}_{12}$ intermetallic $\mathrm{Ni}_{3}(\mathrm{Al}, \mathrm{Ti}) \gamma^{\prime}$ phase, which possesses excellent elevated temperature strength and superior hot corrosion resistance [1,2]. This superalloy is, thus, usually made into turbine blades and turning vanes of aircraft engines due to its excellent properties. However, K465 superalloy turbine parts are prone to damage in severe service conditions. Considering the high cost of replacing defected or damaged parts with new ones, it is more significant and appealing to repair these parts quickly and economically [3]. Laser forming repairing (LFR), as a kind of metal additive manufacturing technology, can be utilized to recover complex shaped damaged parts up to certain depth, without affecting the inherent mechanical properties of the body [4-7].

Unfortunately, cracking is frequently found when LFR technology is used to remanufacture K465 superalloy parts containing high content of $\mathrm{Al}+\mathrm{Ti}(>7.0 \mathrm{wt} . \%)$ and, therefore, this alloy is generally considered as a hard-to-weld material [8]. The main reason for cracking phenomenon is the generation of constitutional liquation and tensile stresses in the heat affected zone (HAZ) during LFR. When the stresses exceed the ability of the material's intrinsic resistance to cracking, cracks appear at grain boundaries in HAZ [9] and then spread into the repaired area along the grain boundaries. It is well known that the formation of liquation cracks depends in the presence of a continuous or 
semi-continuous liquid film at grain boundaries of HAZ [10-13]. Ojo and Chaturvedi [12,14] pointed out that the constitutional liquation of $\gamma^{\prime}$ phase was the main factor in liquation cracks in Inconel 738 welding process. Using Thermo-Calc and Dictra software, Tancret et al. [15] calculated the liquation temperature of $\gamma^{\prime}$ phase in Inconel 738 and pointed out that under a certain particle size and heating rate, $\gamma^{\prime}$ phase could directly dissolve. Zhou and Li et al. [16,17] found that borides, $\gamma+\gamma^{\prime}$ eutectics, MC carbides, and some other phases with low melting points at grain boundaries were the main factors in the formation of liquation cracks in K3 nickel-based cast superalloy during laser cladding. Huang and Qian $[18,19]$ also reported that both $\mathrm{Nb}$ and $\mathrm{B}$ elements enriching at grain boundaries resulted in the loss of weldability of Inconel 718.

Although a few published papers have proposed different mechanisms of grain boundary liquation of nickel-based superalloys during laser heating process, limited works have been carried out on K465 superalloy with higher contents of $\mathrm{Al}+\mathrm{Ti}$ and excellent high temperature mechanical properties. To date, the mechanism of grain boundary liquation in HAZ of K465 superalloy in LFR is still unclear. In order to cut the cost and minimize production cycles, the rapid repairing of damaged $\mathrm{K} 465$ superalloy parts is required by related industries. Therefore, it is necessary to reveal the liquation mechanism for controlling the cracks of LFRed specimens. In this paper, the cracking behavior and grain boundary liquation mechanism of the repaired specimens are investigated.

\section{Materials and Methods}

The LFR experiments were carried out on the LSF-III laser solid forming system (State Key Laboratory of Solidification Processing, Xi'an, China), which consists of a $4 \mathrm{~kW} \mathrm{CO} 2$ laser, a controlled atmosphere chamber and a powder feeding system with a coaxial nozzle. The specimens to be LFRed with dimensions of $\varnothing 30 \mathrm{~mm} \times 10 \mathrm{~mm}$ were cut from a damaged turning vane of aircraft engine, which was made of K465 nickel-based cast superalloy. As part of the damaged turning vane, the specimens experienced a solution treatment for $4 \mathrm{~h}$ at $1120{ }^{\circ} \mathrm{C}$ followed by air cooling. A three-layer single track structure was deposited on the specimen. K465 spherical powder was produced by plasma rotation electrode process and its nominal elemental composition is $0.17 \mathrm{C}, 9.20 \mathrm{Cr}, 2.40 \mathrm{Ti}, 5.5 \mathrm{Al}, 1.81 \mathrm{Mo}, 10.02 \mathrm{~W}$, $9.91 \mathrm{Co}, 1.20 \mathrm{Nb}, 0.005 \mathrm{~B}$, and balance $\mathrm{Ni}(\mathrm{wt} . \%)$. The specimens were preheated at $800^{\circ} \mathrm{C}$ in a furnace prior LFR to reduce thermal stresses. The LFR processing parameters are listed in Table 1.

Table 1. The process parameters of laser forming repairing.

\begin{tabular}{cccccc}
\hline $\begin{array}{c}\text { Laser } \\
\text { Power }(\mathbf{W})\end{array}$ & $\begin{array}{c}\text { Scan Speed } \\
(\mathbf{m m} / \mathbf{s})\end{array}$ & $\begin{array}{c}\text { Spot Diameter } \\
(\mathbf{m m})\end{array}$ & $\begin{array}{c}\text { Powder Feeding } \\
\text { Rate }(\mathrm{g} / \mathbf{m i n})\end{array}$ & $\begin{array}{c}\text { Preheating } \\
\text { Temperature }\left({ }^{\circ} \mathbf{C}\right)\end{array}$ & $\begin{array}{c}\text { Increment } \\
\text { of } \boldsymbol{Z}(\mathbf{m m})\end{array}$ \\
\hline 1000 & 100 & 3 & 10 & 400 & 0.3 \\
\hline
\end{tabular}

The LFRed sample was sectioned perpendicular to the laser scanning direction. After being polished, the sectioned samples were subsequently etched electrolytically in $12 \mathrm{~mL} \mathrm{H}_{3} \mathrm{PO}_{4}+40 \mathrm{~mL}$ $\mathrm{HNO}_{3}+48 \mathrm{~mL} \mathrm{H}_{2} \mathrm{SO}_{4}$ solution at $6 \mathrm{~V}$ for $5 \mathrm{~s}$. The microstructure was observed via optical microscope (OM, OLYMPUS, Nagano, Japan), scanning electron microscopy (SEM, Carl Zeiss, Oberkochen, Germany) and transmission electron microscope (TEM, FEI, Hillsboro, AL, USA). The chemical compositions of all phases were measured through an electron probe microanalyzer (EPMA, SHIMADZU, Kyoto, Japan). A commercial software, Thermo-Calc (Thermo-Calc Software, Stockholm, Sweden), was used to calculate the equilibrium phase diagram.

\section{Results}

\subsection{Main Phases of K465 Nickel-Based Cast Superalloy Substrate}

As shown in Figure 1, K465 cast superalloy substrate mainly contains extensive cubic-shaped $\gamma^{\prime}$ phase, cloddy $\gamma+\gamma^{\prime}$ eutectics, blocky carbides, and some tiny borides at grain boundaries. Figure 1a 
shows the color metallograph of each phase in K465 cast superalloy. The size of $\gamma+\gamma^{\prime}$ eutectic is about $38 \mu \mathrm{m}$. Some blocky MC carbides appear in different sizes and some slight borides exist as white filamentous discontinuities. It should be noted that most of the borides distribute along the grain boundaries, and a few of them are adherent to $\gamma+\gamma^{\prime}$ eutectics in some regions. As shown in Figure 1b, the average size of chain-like $\gamma^{\prime}$ phase distributed at grain boundaries reaches $1.88 \mu \mathrm{m}$, while the average size of intragranular $\gamma^{\prime}$ phase is merely $0.73 \mu \mathrm{m}$. This can be ascribed to micro-segregation of the $\gamma^{\prime}$ phase forming elements at grain boundaries during the solidification process. Ojo et al. [12] reported that solute segregation occurred in the final stage of solidification, which led to the enrichment of Ti at grain boundaries of Inconel 738. Lin et al. [20] also found the $\gamma^{\prime}$ phase forming elements showed similar segregation behavior at the laser deposition area of Rene88DT in SS316L/Rene88DT gradient materials. Thus, the segregation of $\gamma^{\prime}$ phase-forming elements at grain boundaries increases the corresponding solid solution temperature of $\gamma^{\prime}$ phase. During the cooling process, the $\gamma^{\prime}$ phase at grain boundaries initially precipitates at higher temperature. According to Lifshitz, Slyozov, and Wagner (LSW) coarsening theory [21], the enrichment of Ti led to faster coarsening of the $\gamma^{\prime}$ phase at grain boundaries in comparison with that in the grains. Figure 1c presents the diffraction pattern of $\gamma^{\prime}$ phase, indicating the typical super-lattices due to ordering of $\gamma^{\prime}$ phase. The content of boron is slight in K465 superalloy; nevertheless, borides can be formed along the interdendritic regions due to a strong positive micro-segregation tendency [22]. Figure 1d shows the diffraction pattern of borides which is deduced as tetragonal $\mathrm{Cr}_{1.8} \mathrm{~W}_{3.2} \mathrm{~B}_{3}\left(\mathrm{M}_{5} \mathrm{~B}_{3}\right.$ type) borides with lattice parameters of $\mathrm{a}=\mathrm{b}=5.699 \AA$, $c=10.88 \AA$.

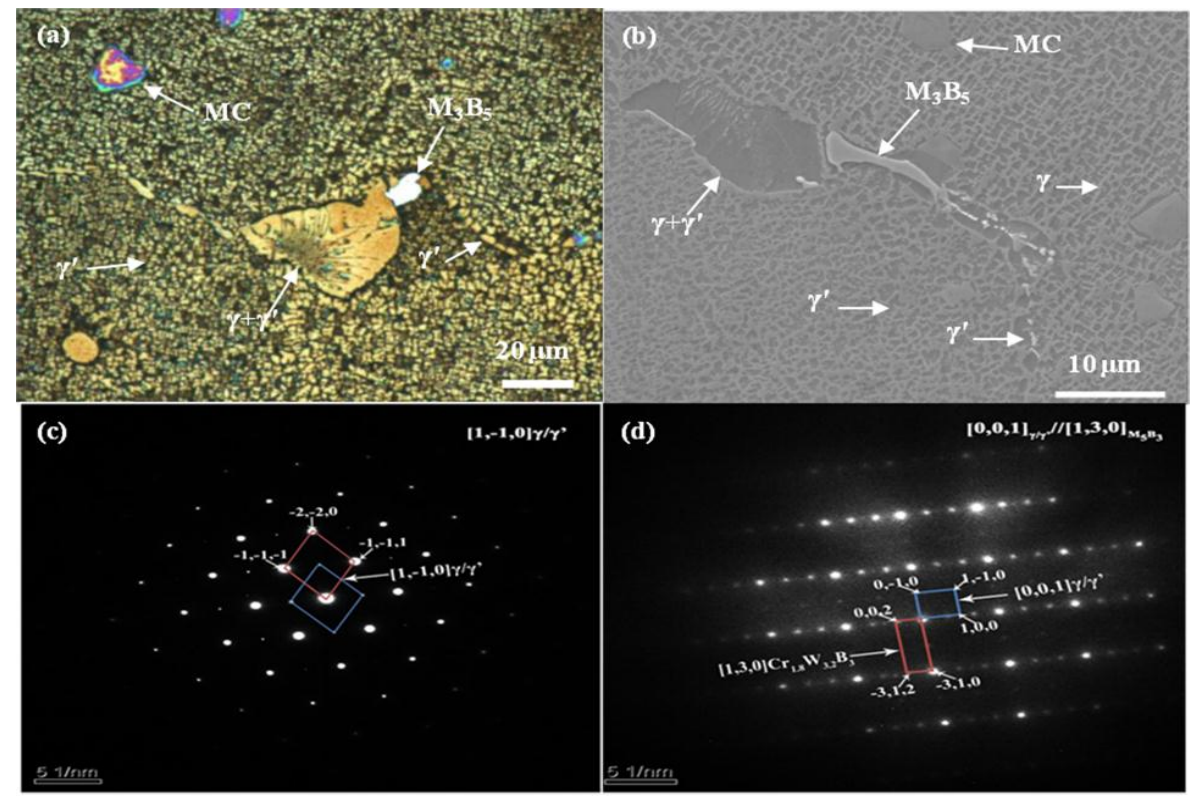

Figure 1. Microstructure of K465 cast superalloy: (a) typical phase distribution; (b) $\gamma^{\prime}$ phase at grain boundaries and within the grains; (c) TEM-SADP of $\gamma^{\prime}$ phase from $[1, \overline{1}, 0]$ zone axis; and (d) TEM-SADP of $\mathrm{M}_{5} \mathrm{~B}_{3}$ from $[1,3,0]$ zone axis.

\subsection{Liquation Cracking Characteristics}

Figure 2 shows a typical microstructure of LFRed K465 superalloy. The LFRed specimen is composed of the substrate zone (SZ), the heat affected zone (HAZ) and the repaired zone (RZ). As can be seen in Figure 2a, columnar dendrites grow epitaxially and directionally from the substrate. At the bottom of RZ, there is a lighter-colored arc zone, namely HAZ of LFRed specimen. In HAZ, cracks appear and extend to the bottom of RZ along the grain boundaries. Figure $2 \mathrm{~b}$ shows the crack features in HAZ, where the crack bends along the grain boundaries and the solidification liquid film is ane side of the grain boundary. The typical liquation crack characteristics can also be observed clearly. 


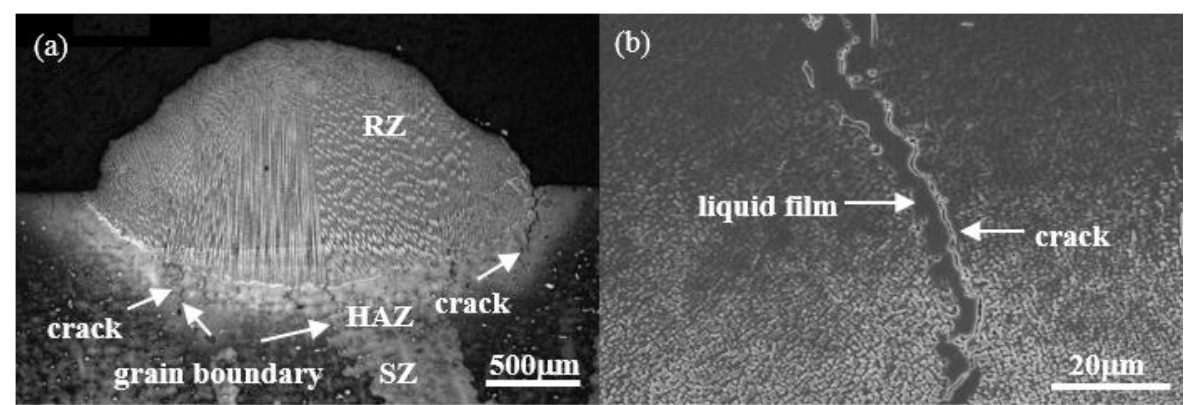

Figure 2. Morphology and cracking characteristics of LFRed K465 specimen: (a) morphology of LFRed specimen and (b) cracking characteristics in HAZ.

Figure 3 shows liquation characteristics at grain boundaries in the HAZ of LFRed K465 superalloy. As shown in Figure 3a, some blocky MC carbides exist in the grain boundary liquation film, and their shapes and sizes are similar to the initial carbides. At grain boundaries near to the RZ, the partial melted carbides are observed, but the liquid film at grain boundaries appears continuous. Obviously, the liquid film is not caused by the liquation of carbides. Figure $3 \mathrm{~b}$ shows the original intragranular $\gamma+\gamma^{\prime}$ eutectic units, which have melted and reformed as some blocky microstructure. Grain boundary liquid films in HAZ are distributed continuously along the grain boundaries and the original $\gamma^{\prime}$ phase at grain boundaries has disappeared. As far away from the bottom of RZ, the width of the grain boundary liquid film reduces and finally disappears. Meanwhile, it could be seen that the width and continuous distribution features of the grain boundary liquid films are obviously contradictory with the morphology and distribution of initial $\gamma+\gamma^{\prime}$ eutectic in substrate. Therefore, it can be concluded that grain boundary liquation should not be induced by the initial $\gamma+\gamma^{\prime}$ eutectic liquation in HAZ.

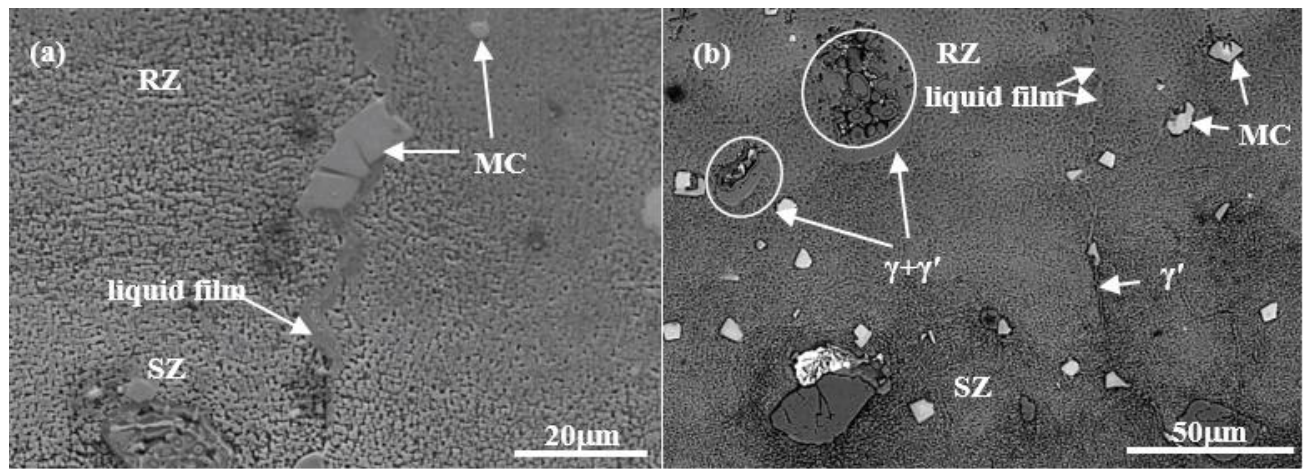

Figure 3. Liquid film and phase distribution in HAZ: (a) liquid film and MC carbides and (b) liquid film and $\gamma+\gamma^{\prime}$ eutectics.

Figure 4 shows the local characteristics of liquid film at grain boundaries. As shown in Figure 4a, liquid film appears at the initial position of $\gamma^{\prime}$ phase at grain boundaries. At the same time, a small fraction of residual $\gamma^{\prime}$ phase is still found at grain boundaries abut on the liquid film. It is also found that the fine $\gamma+\gamma^{\prime}$ eutectics exist at the edge of the liquid film and connect to the $\gamma^{\prime}$ phase at grain boundaries. According to the higher magnification image shown in Figure $4 \mathrm{~b}$, the fine $\gamma+\gamma^{\prime}$ eutectics grow on the $\gamma^{\prime}$ phase at grain boundaries, and they are coherent with the wider liquid film. 


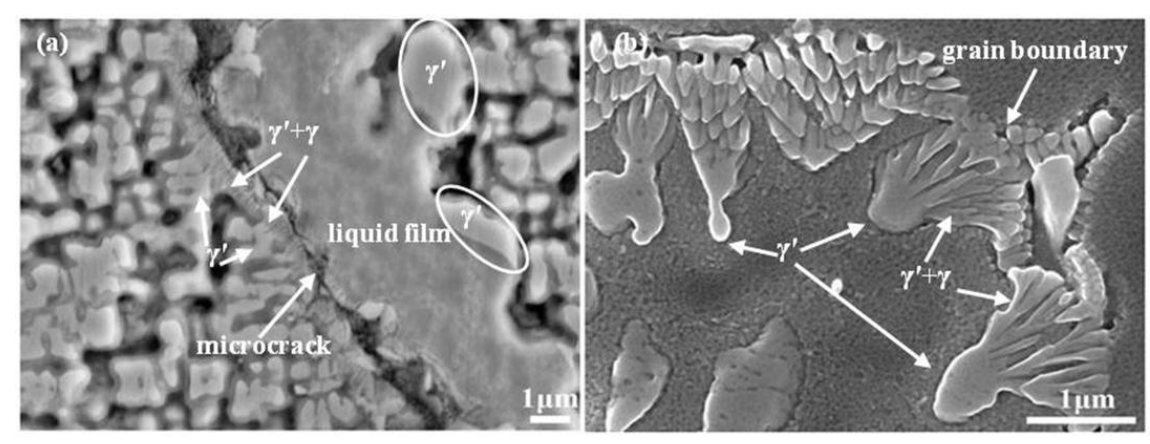

Figure 4. Liquid film in HAZ: (a) $\gamma^{\prime}$ phase in liquid film and (b) fine eutectics grown in liquid film.

\section{Discussion}

\subsection{Grain Boundary Liquation Mechanism in HAZ}

According to Figure 1b, in K465 cast superalloy, low amount of filamentous borides is inadequate to form large continuous liquid film at grain boundaries in HAZ. Figure 3 also shows that the continuous liquid film at grain boundaries is not caused by MC carbides or original $\gamma+\gamma^{\prime}$ eutectic liquation. Figure 4 shows that in LFR process, grain boundary liquation is associated with the $\gamma^{\prime}$ phase at grain boundaries, and eutectic characteristics have emerged in liquation. Ojo et al. $[12,13,23]$ also found the similar phenomenon in TIG-welded Inconel 738LC alloy's HAZ. Based on second phase constitutional liquation theory, Ojo et al. [12] pointed out the constitutional liquation mechanism of $\gamma^{\prime}$ phase at grain boundaries in HAZ and suggested that the $\gamma^{\prime} / \gamma$ phase interface satisfied local thermodynamic equilibrium in the rapid heating process. Firstly, $\gamma^{\prime}$ particles dissolved into $\gamma$ phase. However, rapid heating made the $\gamma^{\prime}$ phase dissolve incompletely, so the residual $\gamma^{\prime}$ phase and the surrounding $\gamma$ phase could satisfy eutectic composition conditions. Then the eutectic reaction occurred and liquated in the form of $\gamma+\gamma^{\prime} \rightarrow \mathrm{L}$ upon the temperature reaching the eutectic temperature $T_{\mathrm{E}}$ [14]. Ojo et al. [14] hypothesized the liquation process of $\gamma^{\prime}$ phase at grain boundaries, but they did not verify whether the $\gamma^{\prime}$ phase at grain boundaries and the surrounding $\gamma$ phase component can achieve eutectic composition or not, and why the liquation cracks occur at grain boundary, which is a necessary condition of liquation in the form of the eutectic-type at the grain boundaries. The liquation of $\gamma^{\prime}$ and $\gamma$ phases with the smaller sizes, which distribute at the grain boundaries, occurs near the bottom of $\mathrm{RZ}$, where the temperature is higher and elements diffuse faster. It can be deduced that the phase transition process of $\gamma^{\prime}$ and $\gamma$ phases in local areas will not deviate far from the equilibrium phase transition process. Thus, studying the equilibrium phase transition of the $\gamma^{\prime}$ phase at grain boundaries and the surrounding $\gamma$ phase in local areas can partly explain the region of the phase transition trend.

The elemental contents of the $\gamma^{\prime}$ phase at grain boundaries, intragranular $\gamma^{\prime}$ phase, and intragranular $\gamma$ phase in K465 cast superalloy substrate were determined by EPMA, and the results are listed in Table 2. The contents of boron (B) and carbon (C) are low and their solubilities in both $\gamma$ and $\gamma^{\prime}$ phases are limited. Their effect on the local compositions around the $\gamma^{\prime}$ phase is negligible so the contents are not tested. According to Table 2, the contents of $\mathrm{Ni}, \mathrm{Nb}, \mathrm{Al}$, and Ti reach the highest levels in $\gamma_{a g b}^{\prime}$ ( $\gamma^{\prime}$ phase at grain boundaries) while they are the least in $\gamma_{i}(\gamma$ phase). The contents of Co, Cr, Mo, and $\mathrm{W}$ are the lowest in $\gamma_{a g b}^{\prime}$, whereas they reach the highest levels in $\gamma_{i}$. The elemental composition in $\gamma_{i}^{\prime}$ (intragranular $\gamma^{\prime}$ phase) are between that in $\gamma_{a g b}^{\prime}$ and $\gamma_{i}$. Since the $\gamma$ phase morphology is a thin layer at grain boundaries, electron probe cannot measure it accurately, but its elements' contents are assumed to be close to the $\gamma_{i}$ phase. Considering of $\gamma_{a g b}^{\prime}$ and $\gamma$ phase at grain boundaries, each element content at the local area consisting of $\gamma^{\prime}$ and $\gamma$ phase at grain boundaries ranges between that in $\gamma_{a g b}^{\prime}$ and $\gamma_{i}$. Therefore, the content of each element in the local area have a maximum and minimum, which are the contents of the $\gamma_{a g b}^{\prime}$ and $\gamma$ phases, respectively. To detect the phase transition behavior of the $\gamma^{\prime}$ and $\gamma$ phases at grain boundaries in the heating process, thermodynamic calculation could be used. In order to explain the influence of composition variation on the phase transition trend, it is 
necessary to select and analyze several values between the maximum and minimum values of each element at the local area.

Table 2. Chemical compositions of $\gamma$ and $\gamma^{\prime}$ phases in K465 superalloy substrate by EPMA (mass fraction, $\% ; \gamma_{a g b}^{\prime}-\gamma^{\prime}$ phase at grain boundaries; $\gamma_{i}^{\prime}$-intragranular $\gamma^{\prime}$ phase; $\gamma_{i}$-intragranular $\gamma$ phase).

\begin{tabular}{ccccccccc}
\hline \multirow{2}{*}{ Phases } & \multicolumn{7}{c}{ Element } \\
\cline { 2 - 9 } & Ni & Co & Cr & Mo & Nb & Al & Ti & W \\
\hline$\gamma^{\prime}{ }_{a g b}^{\prime}$ & $70.5 \pm 0.4$ & $8.39 \pm 0.4$ & $4.33 \pm 0.2$ & $0.57 \pm 0.1$ & $1.26 \pm 0.2$ & $8.29 \pm 0.1$ & $4.41 \pm 0.4$ & $2.26 \pm 0.9$ \\
$\gamma^{\prime}{ }_{i}$ & $69.1 \pm 0.5$ & $9.23 \pm 0.4$ & $5.72 \pm 0.8$ & $0.80 \pm 0.1$ & $0.94 \pm 0.1$ & $7.26 \pm 0.7$ & $3.22 \pm 0.4$ & $3.75 \pm 0.9$ \\
$\gamma_{i}$ & $61.5 \pm 1.2$ & $12.3 \pm 0.6$ & $11.9 \pm 0.6$ & $1.67 \pm 0.1$ & $0.57 \pm 0.1$ & $5.56 \pm 0.1$ & $2.16 \pm 0.2$ & $4.42 \pm 0.3$ \\
\hline
\end{tabular}

Using the data listed in Table 3, equilibrium phase transition processes were calculated by Thermo-Calc software. The results are shown in Figure 5. Figure 5a shows the equilibrium phase transition of group a. Below a temperature of $1317^{\circ} \mathrm{C}$, no liquid forms and $\gamma^{\prime}$ particles dissolve into the $\gamma$ phase gradually with the increase in temperature, which increases the content of the $\gamma$ phase. From 1317 to $1339{ }^{\circ} \mathrm{C}$, the volume fractions of both $\gamma^{\prime}$ and $\gamma$ phases reduce with the increase of liquid content, indicating the occurrence of the $\gamma+\gamma^{\prime} \rightarrow$ L eutectic liquation reaction. When the temperature rises from 1339 to $1344{ }^{\circ} \mathrm{C}$, the residual $\gamma^{\prime}$ particles directly dissolve into the liquid. In the whole heating process, the temperature for $\gamma+\gamma^{\prime} \rightarrow$ L eutectic transformation is the lowest and the liquation may occur at this temperature.

Table 3. Typical chemical constituents for thermodynamic calculation (mass fraction, $\%$ ).

\begin{tabular}{ccccccccc}
\hline \multirow{2}{*}{ Group } & \multicolumn{7}{c}{ Element } \\
\cline { 2 - 9 } & $\mathbf{N i}$ & Co & Cr & Mo & Nb & Al & Ti & W \\
\hline a & 70.50 & 8.39 & 4.33 & 0.57 & 1.26 & 8.29 & 4.41 & 2.26 \\
b & 68.70 & 9.04 & 5.89 & 0.76 & 1.14 & 7.82 & 4.03 & 2.62 \\
c & 64.52 & 10.99 & 9.35 & 1.30 & 0.80 & 6.46 & 2.91 & 3.67 \\
d & 61.50 & 12.3 & 11.9 & 1.67 & 0.57 & 5.56 & 2.16 & 4.42 \\
\hline
\end{tabular}

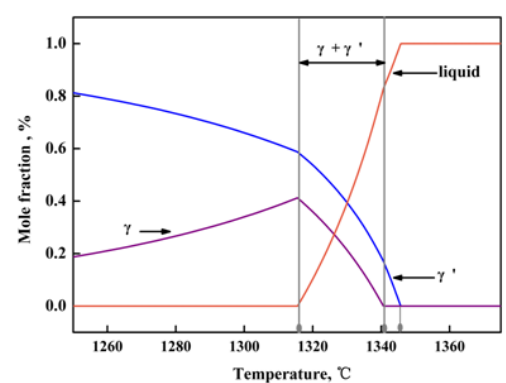

(a)

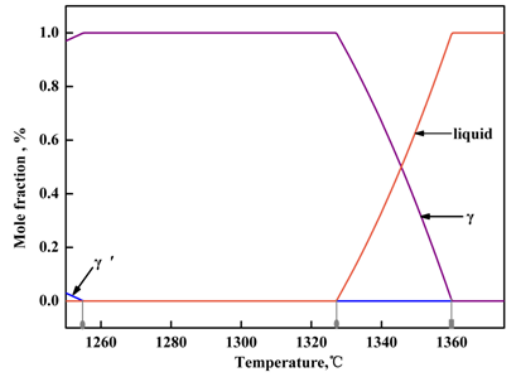

(c)

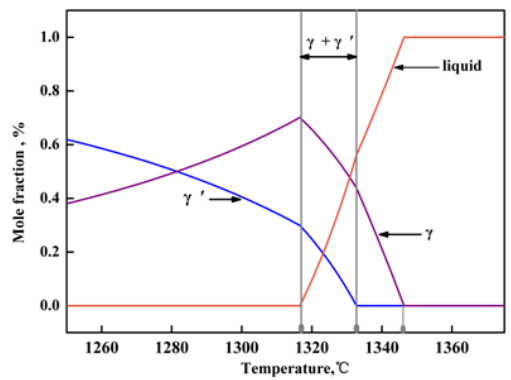

(b)

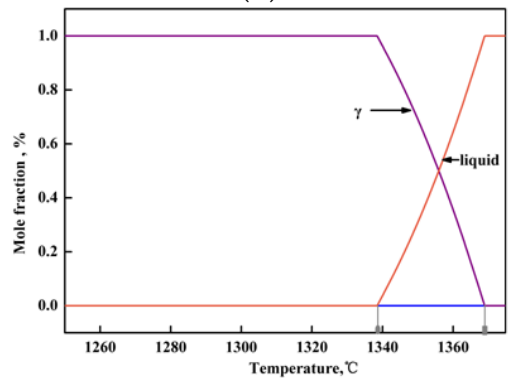

(d)

Figure 5. Calculated phase diagram based on chemical constituents in Table 2: (a) constituents of group a; (b) constituents of group b; (c) constituents of group c; and (d) constituents of group d. 
Figure $5 b$ is about the equilibrium phase transition diagram of group $b$. It is similar to the tendency as shown in Figure 5a, but the reaction of $\gamma+\gamma^{\prime} \rightarrow \mathrm{L}$ ends at $1332{ }^{\circ} \mathrm{C}$. Between the temperature 1332 and $1345^{\circ} \mathrm{C}$, the $\gamma$ phase liquates directly.

Figure $5 c$ shows the equilibrium phase transition diagram of group c. As shown in Figure $5 c$, when the temperature is below $1254^{\circ} \mathrm{C}$, as the temperature increases, $\gamma^{\prime}$ particles gradually dissolve into the $\gamma$ phase. At $1254{ }^{\circ} \mathrm{C}$, solid solution forms and a $\gamma$ single-phase region appears. When the temperature rises to $1327^{\circ} \mathrm{C}$, the $\gamma$ phase begins to liquate.

Figure $5 \mathrm{~d}$ indicates the phase diagram of group d. $\gamma^{\prime}$ particles completely dissolve into the $\gamma$ phase and become a $\gamma$ single-phase region, and it begins to liquate at $1338^{\circ} \mathrm{C}$.

As shown in Figure $5 \mathrm{a}-\mathrm{d}$, content variation of each element at local area will affect the phase transition behavior in the heating process. When the content of each element at the local area is near $\gamma_{\text {agb }}^{\prime}$ (group a in Table 3), or slightly deviate from $\gamma_{\text {agb }}^{\prime}$ (group b in Table 3), phase transition behavior in heating is similar to the scenarios shown in Figure $5 \mathrm{a}, \mathrm{b}$, and the $\gamma^{\prime}$ phase is the first to dissolve into the $\gamma$ phase, then the eutectic-type liquation occurs, then the starting temperature of the liquation is lower $\left(1317 \sim 1318^{\circ} \mathrm{C}\right)$. When the content of each element in the local area deviates farther from that of the $\gamma^{\prime}$ phase at grain boundaries (such as Table 3c,d), the behavior of temperature-phase transition is similar to the situation as shown in Figure $5 c, d$, which means that the $\gamma^{\prime}$ phase first completely dissolve into the $\gamma$ phase, then the $\gamma$ phase begins to liquate, and the liquation temperature is higher $\left(1327 \sim 1338^{\circ} \mathrm{C}\right)$.

According to the analysis of metallographic particles, as shown in Figure 1, the size of the $\gamma_{a g b}^{\prime}$ phase is the largest, then $\gamma_{i}^{\prime}$, while the $\gamma$ phase has the smallest size filling around the granular $\gamma^{\prime}$ phase as a thin layer. The local compositions composing of $\gamma^{\prime}$ phase and $\gamma$ phase at grain boundaries, probably have the similar element contents to group a, so the phase transition process is probably similar to the situation as shown in Figure 5a,b in heating process, then the eutectic-type liquation reaction of $\gamma+\gamma^{\prime} \rightarrow$ L occurs, and the liquation reaction temperature is lower. In other words, as long as the $\gamma^{\prime}$ phase and $\gamma$ phase at grain boundaries at the local area can satisfy the eutectic liquid composition, the liquation reaction will occur provided the temperature rises up to the eutectic liquation temperature.

\subsection{Transition Characteristics of the Intragranular $\gamma^{\prime}$ Phase}

Figure 6 shows the transition characteristic of intragranular $\gamma^{\prime}$ phase in HAZ of LFRed K465 specimen. The top of Figure 6a is near RZ and the bottom is near SZ. As can be seen from Figure 6a, the intragranular initial $\gamma^{\prime}$ phase in HAZ almost dissolves completely and reprecipitates in smaller size near RZ. There is no liquation phenomenon. Nevertheless, the intragranular initial $\gamma^{\prime}$ particles partly dissolve near SZ. Figure $6 \mathrm{~b}$ shows microstructure characteristic of the partly-dissolved $\gamma^{\prime}$ phase. It can be seen that there is no liquid film around the residual $\gamma^{\prime}$ phase, and the precipitated fine $\gamma^{\prime}$ approximates vermicular, not cubic, in shape. These features suggest the intragranular $\gamma^{\prime}$ phase did not liquate in the heating process.
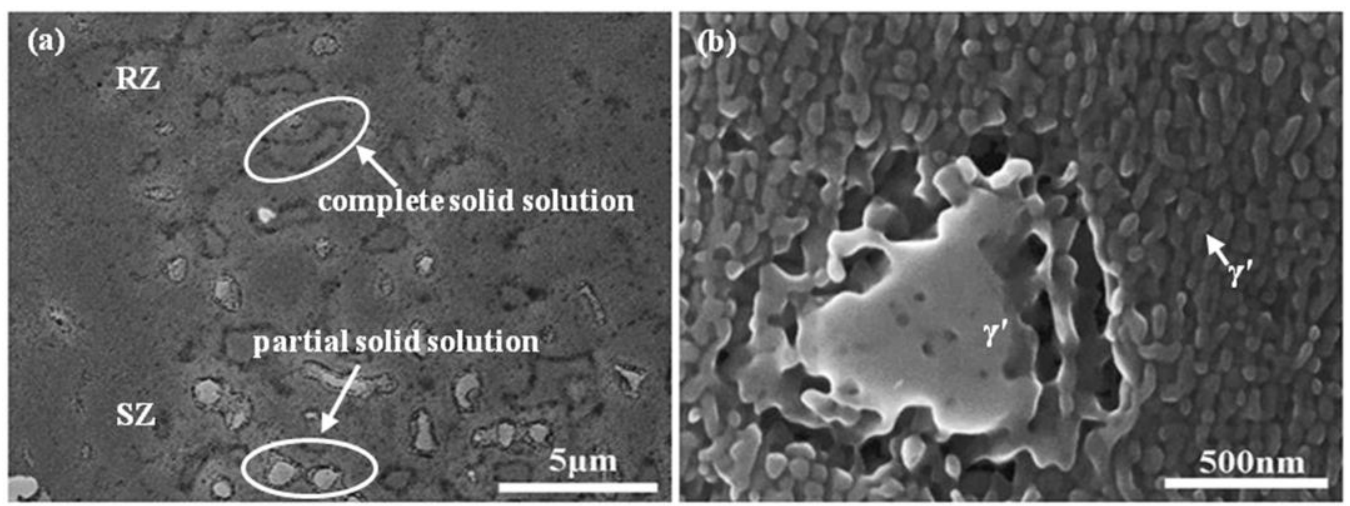

Figure 6. Phase transition of intragranular $\gamma^{\prime}$ in HAZ: (a) low magnification and (b) high magnification. 
As can be seen in Table 2, there exists micro-segregation of alloying elements in K465 cast superalloy. The element contents of intragranular $\gamma^{\prime}$ and intergranular $\gamma^{\prime}$ are different. The calculation based on the equilibrium phase transition of the intragranular $\gamma^{\prime}$ phase composition is shown in Figure 7. The phase transition tendency as shown in Figure 7 is similar to that in Figure 5c. As the temperature increases, the $\gamma^{\prime}$ phase first dissolves in the $\gamma$ phase, then the $\gamma$ single-phase begins to liquate. There is no indication of the eutectic-type liquation. Considering the influence of a thin layer $\gamma$ phase on the local compositions around the intragranular $\gamma^{\prime}$, the element compositions of the local region consisting of the intragranular $\gamma^{\prime}$ and $\gamma$ phases are between that in $\gamma_{i}^{\prime}$ and $\gamma_{i}$ phase; therefore, the phase transition behavior in heating is similar to the change from Figures 7 and $5 \mathrm{~d}$, which shows that eutectic-type liquation does not occur inside of the grains. The local compositions around the intragranular $\gamma^{\prime}$ phase only completely dissolve in the $\gamma$ phase firstly, then the $\gamma$ phase directly liquates, and the initial liquation temperature is higher than that of the local composition around the $\gamma^{\prime}$ phase at grain boundaries in eutectic-type liquation reaction.

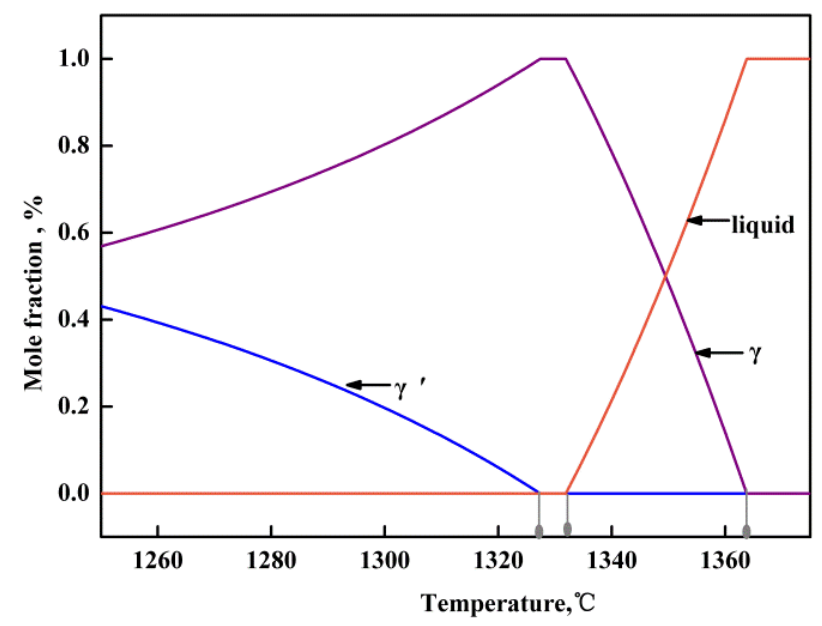

Figure 7. Calculated phase diagram based on the constituents of the intragranular $\gamma^{\prime}$ phase.

\subsection{The Influence of Borides on Grain Boundary Liquation}

As shown in Figure 1, there exist $\mathrm{M}_{5} \mathrm{~B}_{3}\left(\mathrm{Cr}_{1.8} \mathrm{~W}_{3.2} \mathrm{~B}_{3}\right)$ borides at grain boundaries. Zheng [23] indicated that the liquation of borides corroded the $\gamma+\gamma^{\prime}$ eutectic, which induced the liquation of the $\gamma+\gamma^{\prime}$ eutectic and decreased the initial $\gamma+\gamma^{\prime}$ eutectic melting temperature. Fine filamentous $\mathrm{M}_{5} \mathrm{~B}_{3}$ borides with a low melting point are susceptible to liquation at grain boundaries [24]. However, it is insufficient to form continuous or semi-continuous liquid films due to its small volume fraction. Nonetheless, borides can wet the grain boundary and release boron atoms along the grain boundaries.

The effect of B content (group a) on eutectic-type liquation temperature was calculated based on equilibrium transition and the result is shown in Figure 8. As shown in Figure 8, the increase of B element content can lower the initial temperature of the eutectic-type liquation $\left(T_{\mathrm{E}}-\right.$ start $)$, but it hardly affects the complete liquation temperature $\left(T_{\mathrm{E}-\text { end }}\right)$. Similar results were also proposed by Wang [25], in which 0.07 wt. \% increment of B reduced the $T_{\mathrm{E}-\text { start }}$ by almost $35^{\circ} \mathrm{C}$, but $T_{\mathrm{E}-\text { end }}$ was unaffected in IC6 superalloy. That is to say, B will further promote the liquation of grain boundary $\gamma^{\prime}$ and the surround the $\gamma$ phase during the heating process. 


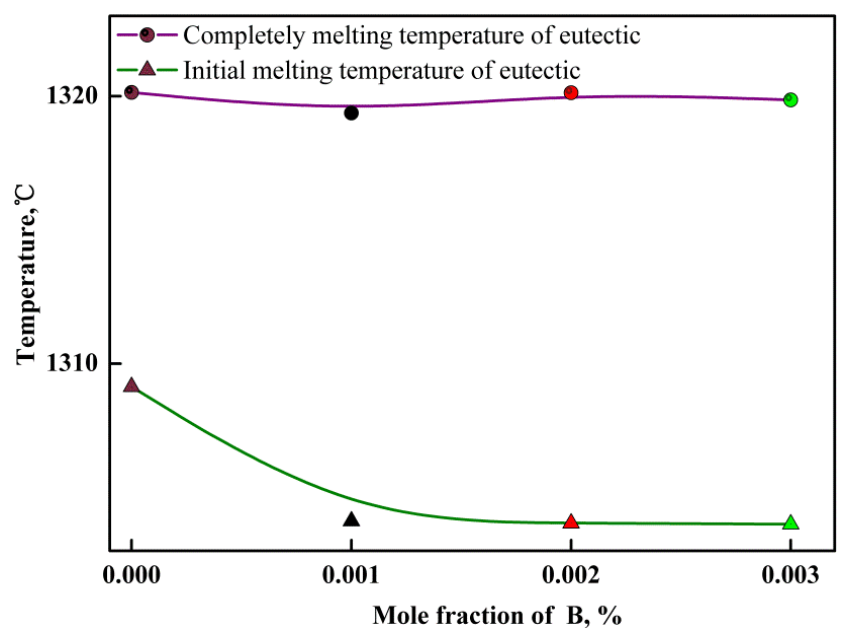

Figure 8. Influence of element B on $\gamma+\gamma^{\prime}$ eutectic liquation reaction.

\section{Conclusions}

The damage accumulation and micro-crack nucleation in HAZ of the LFRed K465 specimens result from the grain boundary liquation. The continuous or semi-continuous liquid films in HAZ originate from the eutectic-type liquation of the local compositions, which consist of the larger size $\gamma^{\prime}$ phase and the thin layer $\gamma$ phase at grain boundaries.

Element micro-segregation makes the $\gamma^{\prime}$ and $\gamma$ phases at grain boundaries liquate in the eutectic-type, while the intragranular $\gamma^{\prime}$ phase does not liquate in the rapid heating process.

Liquation film is not induced by the liquation of the initial $\gamma+\gamma^{\prime}$ eutectics, blocky MC carbides, and slight filamentous borides along the grain boundaries in HAZ of the LFRed K465 specimens. However, the addition or dissolution of a small quantity of $\mathrm{M}_{5} \mathrm{~B}_{3}$ borides at grain boundaries can reduce the eutectic initial melting temperature.

Acknowledgments: The work was supported by National Natural Science Foundation of China (Nos. 51323008, 51271213 and 51475380), the Open Fund of National Defence Key Disciplines Laboratory of Light Alloy Processing Science and Technology in Nanchang Hangkong University (gf 201401002) and the Programme of Introducing Talents of Discipline to Universities, China (08040).

Author Contributions: Weidong Huang and Haiou Yang conceived and designed the experiments; Xinghua Wang and Qiuge Li performed the experiments; Xin Lin and Menghua Song analyzed the data; Qiuge Li wrote the paper.

Conflicts of Interest: The authors declare no conflict of interest.

\section{Abbreviations}

The following abbreviations are used in this manuscript:

$\begin{array}{ll}\text { LFR } & \text { Laser Forming Repairing } \\ \text { LFRed } & \text { Laser Forming Repaired } \\ \text { SZ } & \text { Substrate Zone } \\ \text { HAZ } & \text { Heat Affected Zone } \\ \text { RZ } & \text { Repaired Zone }\end{array}$

\section{References}

1. Yang, J.X.; Zheng, Q.; Sun, X.F.; Guan, H.R.; Hu, Z.Q. Formation of $\mu$ Phase During Thermal Exposure and Its Effect on The Properties of K465 Superalloy. Scr. Mater. 2006, 55, 331-334. [CrossRef]

2. Yang, J.X.; Zheng, Q.; Sun, X.F.; Guan, H.R.; Hu, Z.Q. Relative Stability of Carbides and Their Effects on The Properties of K465 Superalloy. Mater. Sci. Eng. A 2006, 429, 341-347. [CrossRef] 
3. Yaso, M.; Morito, S.; Ohba, T.; Kubota, K. Microstructure of Martensite in Fe-C-Cr Steel. Mater. Sci. Eng. A 2008, 481, 770-773. [CrossRef]

4. Lin, X.; Yue, T.M.; Yang, H.O.; Huang, W.D. Microstructure and Phase Evolution in Laser Rapid Forming of a Functionally Graded Ti-Rene88DT Alloy. Acta Mater. 2006, 54, 1901-1915. [CrossRef]

5. Gaumann, M.; Henry, S.; Cleton, F.; Wegniere, J.D.; Kurz, W. Epitaxial Laser Metal Forming: Analysis of Microstructure Formation. Mater. Sci. Eng. A 1999, 271, 232-241. [CrossRef]

6. Liu, F.C.; Lin, X.; Huang, C.P.; Song, M.H.; Yang, G.L.; Chen, J.; Huang, W.D. The Effect of Laser Scanning Path on Microstructures and Mechanical Properties of Laser Solid Formed Nickel-base Superalloy Inconel 718. J. Alloy. Compd. 2011, 205, 4505-4509. [CrossRef]

7. Lin, X.; Yang, H.O.; Chen, J.; Huang, W.D. Microstructure Evolution of 316L Stainless Steel During Laser Rapid Forming. Acta Metall. Sin. 2006, 42, 361-368.

8. Henderson, M.B.; Arrell, D.; Larsson, R.; Heobel, M.; Marchant, G. Nickel Based Superalloy Welding Practices for Industrial Gas Turbine Applications. Sci. Technol. Weld. Join. 2004, 9, 13-21. [CrossRef]

9. Montazeri, M.; Ghaini, F.M. The Liquation Cracking Behavior of IN738LC Superalloy During Low Power Nd:YAG Pulsed Laser Welding. Mater. Charact. 2012, 67, 65-73. [CrossRef]

10. Richards, N.L.; Nakkalil, R.; Chaturvedi, M.C. The Influence of Electron-Beam Welding Parameters on Heat-Affected-Zone Microfissuring in INCOLOY 903. Metall. Mater. Trans. A 1994, 25, 1733-1745. [CrossRef]

11. Ojo, O.A. Intergranular Liquation Cracking in Heat Affected Zone of A Welded Nickel Based Superalloy in As Cast Condition. Mater. Sci. Technol. 2007, 23, 1149-1155. [CrossRef]

12. Ojo, O.A.; Richards, N.L.; Chaturvedi, M.C. Contribution of Constitutional Liquation of Gamma Prime Precipitate to Weld HAZ Cracking of Cast Inconel 738 Superalloy. Scr. Mater. 2004, 50, 641-646. [CrossRef]

13. Ojo, O.A.; Richards, N.L.; Chaturvedi, M.C. Microstructural Study of Weld Fusion Zone of TIG Welded IN738LC Nickel-based Superalloy. Scr. Mater. 2004, 51, 683-688. [CrossRef]

14. Ojo, O.A.; Chaturvedi, M.C. On The Role of Liquated $\gamma^{\prime}$ Precipitates in Weld Heat Affected Zone Microfissuring of a Nickel-based Superalloy. Mater. Sci. Eng. A 2005, 403, 77-86. [CrossRef]

15. Tancret, F. Thermo-Calc and Dictra Simulation of Constitutional Liquation of Gamma Prime $\left(\gamma^{\prime}\right)$ During Welding of Ni Base Superalloys. Comput. Mater. Sci. 2007, 41, 13-19. [CrossRef]

16. Zhou, Z.H.; Zhu, B.D. The Study on The Laser Cladding Process and Cracking of Cast Ni-Based Superalloy K3. J. Mater. Eng. 1996, 1, 32-35.

17. Li, X.L.; Liu, J.W.; Zhong, M.L. Research on Laser Cladding Superalloy K403. Appl. Laser 2002, 22, $283-286$.

18. Huang, X.; Chaturvedi, M.C.; Richards, N.L.; Jackman, J. The Effect of Grain Boundary Segregation of Boron in Cast Alloy 718 HAZ Microfissuring-A SIMS Analysis. Acta Mater. 1997, 45 1997, 45, 3095-3107. [CrossRef]

19. Qian, M.; Lippold, J.C. The Effect of Annealing Twin-generated Special Grain Boundaries on HAZ Liquation Cracking of Nickel-base Superalloys. Acta Mater. 2003, 51, 3351-3361. [CrossRef]

20. Lin, X.; Yue, T.M. Phase Formation and Microstructure Evolution in Laser Rapid Forming of Graded SS316L/Rene88DT Alloy. Mater. Sci. Eng. A 2005, 402, 294-306. [CrossRef]

21. Lifshitz, I.M.; Slyozov, V.V. The Kinetics of Precipitation From Supersaturated Solid Solutions. J. Phys. Chem. Solids 1961, 19, 35-50. [CrossRef]

22. Seo, S.M.; Kim, Y.S.; Lee, J.H.; Jo, C.Y.; Miyahara, H.; Ogi, K. Eta Phase and Boride Formation in Directionally Solidified Ni-Base Superalloy IN792 + Hf. Metall. Mater. Trans. A 2007, 38, 883-893. [CrossRef]

23. Zheng, Y.R.; Zhang, D.T. Color Metallographic Investigation of Superalloys and Steels; National Defence Industry Press: Beijing, China, 1999; pp. 5-10.

24. Osoba, L.O.; Ding, R.G.; Ojo, O.A. Improved Resistance to Laser Weld Heat-affected Zone Microfissuring in a Newly Developed Superalloy HAYNES 282. Metall. Mater. Trans. 2012, 43, 4281-4295. [CrossRef]

25. Wang, X.P.; Zheng, Y.R.; Xiao, C.B.; Wang, B.L.; Han, Y.F. Study of Effect of Boron Content on Solidification Process of IC6 Alloys. J. Aeronaut. Mater. 2000, 20, 21-27.

(C) 2016 by the authors; licensee MDPI, Basel, Switzerland. This article is an open access article distributed under the terms and conditions of the Creative Commons by Attribution (CC-BY) license (http:/ / creativecommons.org/licenses/by/4.0/). 